\title{
Integration of Active Solar Thermal Technologies in Greenhouses: A Mini Review
}

\author{
Ding Ding* \\ School of Architecture and Civil Engineering, Xihua University, Chengdu, China
}

Traditional agricultural greenhouses have been used to grow vegetables in the winter without any auxiliary heating. However, crop production is highly influenced by soil and air temperatures, humidity, and solar radiation. The aim of this paper is to review the recent active solar thermal technologies that help reduce the energy demand for greenhouse climate control and achieve intensive crop production. The review is categorized into the following topics: 1) locations for collector installation; 2) discussion on the different types of solar collectors, which include metal-based, glass-based, ceramic-based, plastic-based,

OPEN ACCESS

Edited by:

Ahmed Amine Hachicha, University of Sharjah,

United Arab Emirates

Reviewed by:

Hasila Jarimi,

National University of Malaysia, Malaysia

Lahoucine Gourdo,

Université Ibn Zohr, Morocco

Shiva Gorjian,

Tarbiat Modares University, Iran

*Correspondence:

Ding Ding

1220180021@mail.xhu.edu.cn ding7777ding@foxmail.com

Specialty section: This article was submitted to

Solar Energy,

a section of the journal

Frontiers in Energy Research

Received: 12 August 2021

Accepted: 29 October 2021

Published: 16 November 2021

Citation:

Ding D (2021) Integration of Active Solar Thermal Technologies in

Greenhouses: A Mini Review.

Front. Energy Res. 9:757553.

doi: 10.3389/fenrg.2021.757553 and hybrid photovoltaic/thermal types for greenhouse applications; 3) heat release systems in active greenhouses in terms of basal heating, backwall heating, and air heating systems; and 4) short-term and long-term heat storage systems for greenhouses. Future studies on active solar greenhouses might focus on microclimate prediction, long-term heat storage, and system optimization.

Keywords: thermal collector, greenhouse construction, solar absorption, heat release, heat storage, crop growth

\section{INTRODUCTION}

In recent years, the energy demand of civil building environmental control has been greatly reduced (Kelly et al., 2020), and substantial energy-saving potential still exists in other sectors, such as agricultural production buildings, because crop production directly accounts for approximately $10-12 \%$ of anthropogenic greenhouse gas emissions (Wu et al., 2020). Traditional solar greenhouses are passive solar systems with little human intervention in the heating process, where all heat transfer processes are selfregulated (Tong et al., 2018). However, active heating uses mechanical equipment and materials to change the heat transfer and capture process to improve crop production (Hassanien et al., 2016). To reduce the consumption of unsustainable energies, solar collectors have been applied to greenhouse projects.

The scope of this paper is to review the recent active solar thermal technologies that help reduce the energy demand for greenhouse climate control and achieve intensive crop production. Compared with related publications, this paper 1) introduces a new type of all-ceramic solar collector that can be used in greenhouse construction; 2) analyzes the four installation locations of solar collectors in greenhouse projects and proposes the inner surfaces of the backwalls; and 3) categorizes heat release systems in active solar greenhouses as basal heating systems, backwall heating systems, and air heating systems.

\section{SOLAR COLLECTOR CATEGORIES}

The most widely-used solar thermal collectors include flat-plate collectors, evacuated tube collectors, and compound parabolic concentrators (Gorjian et al., 2020a). This section mainly discusses solar 
TABLE 1 | Comparison of different solar collector types.

\begin{tabular}{|c|c|c|c|c|c|c|}
\hline Category & Form & $\begin{array}{l}\text { Outlet fluid } \\
\text { temperature }\end{array}$ & $\begin{array}{l}\text { Thermal } \\
\text { efficiency }\end{array}$ & Service life & Financial cost & Main references \\
\hline Metal & Plate & Medium & $65-80 \%$ & $15-20$ years & $\approx \$ 271 / \mathrm{m}^{2}$ & $\begin{array}{l}\text { (Attar et al., 2013; Yang et al., 2013; Akram et al., } \\
\text { 2021) }\end{array}$ \\
\hline Ceramic & Plate & Medium & $39-65 \%$ & $>100$ years & $\approx \$ 28 / \mathrm{m}^{2}$ & (Zukowski and Woroniak, 2017; Ding, 2018) \\
\hline Plastic & Plate & Medium & $14-69 \%$ & No data & $\begin{array}{l}\text { Less than metal, glass and PV/T } \\
\text { collectors }\end{array}$ & (Jona and Rosso, 2008; Fabrizio, 2012) \\
\hline
\end{tabular}

collectors made of metal, glass, ceramic, and plastic in the form of plates or tubes. In addition, a photovoltaic/thermal (PV/T) Solar System is presented (Table 1).

\section{Metal-Based Collectors}

Metal-based collectors, usually in the form of flat plates, have dominated the market at temperatures ranging from $30^{\circ} \mathrm{C}$ to $80^{\circ} \mathrm{C}$ in greenhouses in the past decades due to their affordable investment and simple installation (Jeon et al., 2016). However, beyond this temperature range, the efficiency of the metal collector is relatively poor. In particular, at high altitudes, the metal plate collector tends to be damaged due to water freezing.

In addition to flat plates, metal plates used in greenhouses have various cross-sectional configurations to absorb more solar irradiation, such as corrugated, reverse-corrugated, trapeziform, and reverse-trapeziform plates (Ozgener and Hepbasli, 2005; Said et al., 2016). Previous studies have shown that corrugated plate collectors have an advantage over other forms in absorbing more solar radiation (Zheng et al., 2017).

The working medium flow inside or on the surface of the plate can be both liquid and air (Zheng et al., 2017). In addition, the service life of the metal collector is only 15-20 years owing to the deterioration of the absorptive coating on the surface of the plate (Yang et al., 2013).

\section{Glass-Based Collectors}

Among all solar collectors used in greenhouses at low-medium temperatures, the glass collector, normally in the form of an evacuated tube, is the most efficient (Chopra et al., 2018). The glass collector can generate heat over $100^{\circ} \mathrm{C}$ at a relatively low cost (Kim et al., 2013). In the past 20 years, due to the development of double glass vacuum tube production, its cost has been greatly reduced. As a result, the market for glass collectors has surpassed that of metal collectors (Teles et al., 2019). According to the market conditions in 2018, $77.8 \%$ of newly installed solar collectors were glass (Chopra et al., 2018). Although concentrating glass collectors or parabolic trough collectors can produce heat above $300^{\circ} \mathrm{C}$, they are not commonly used in greenhouses (Kasaeian et al., 2017).

The structures of non-concentrating glass collectors are broadly classified into all-glass, heat-pipe, straight-flow (concentric cannula), and U-shaped tubes (Ramírez-
Minguela et al., 2018). The glass tube consists of a selectively coated tube (the inner tube) inserted into another borosilicate tube (the outer tube). The vacuum is formed by the process of discharging air from the space between the inner and outer tubes. Vacuum tubes work efficiently because vacuum is a good insulator for heat dissipation (Papadimitratos et al., 2016).

Various types of glass collectors can be used in solar greenhouses for liquid heating, air heating, drying, and other applications. However, due to the destruction of the vacuum space and glass damage, the service life of glass tube collectors is as short as that of metal collectors, which hardly matches the life of a building (Yang et al., 2013).

\section{Ceramic-Based Collectors}

To solve the problems of conventional metal-flat and glass-tube solar collectors such as short service life and relatively high cost, scholars have devoted considerable efforts toward investigating long-life and low-cost solar thermal absorption materials that can be easily integrated into building construction, especially in developing countries. Therefore, a flat-plate collector made of vanadium-titanium black ceramic was invented and implemented (Ding et al., 2021). The ceramic coating has an absorption coefficient of $0.93-0.97$, which barely decays with time (Żukowski et al., 2019). Moreover, this all-ceramic collector costs only $\$ 28 / \mathrm{m}^{2}$ (Ding, 2018), approximately $1 / 20$ of that of conventional collectors (Chopra et al., 2018). Compared with metal plate collectors, ceramic collectors have more abundant cross-sectional forms, such as corrugated, box-shaped, and tubeshaped plates.

Ceramic plate collectors are suitable for integrated installation; i.e., they have the potential to share the structure layer, the waterproof layer, and the insulation layer with the greenhouse in either the frame mode or the plie mode (Figure 1). These modes are appropriate for medium-to-large solar heating systems with limited investments.

\section{Plastic-Based Collectors}

In addition to the all-ceramic plate, another low-cost solar collector made of plastic was developed (Jona and Rosso, 2008). The collector is a $1 \mathrm{~cm}$ black hollow polypropylene plate. The collector consists of an absorber located between a $1 \mathrm{~cm}$ transparent hollow plate at the front and a $5 \mathrm{~cm}$ insulation 

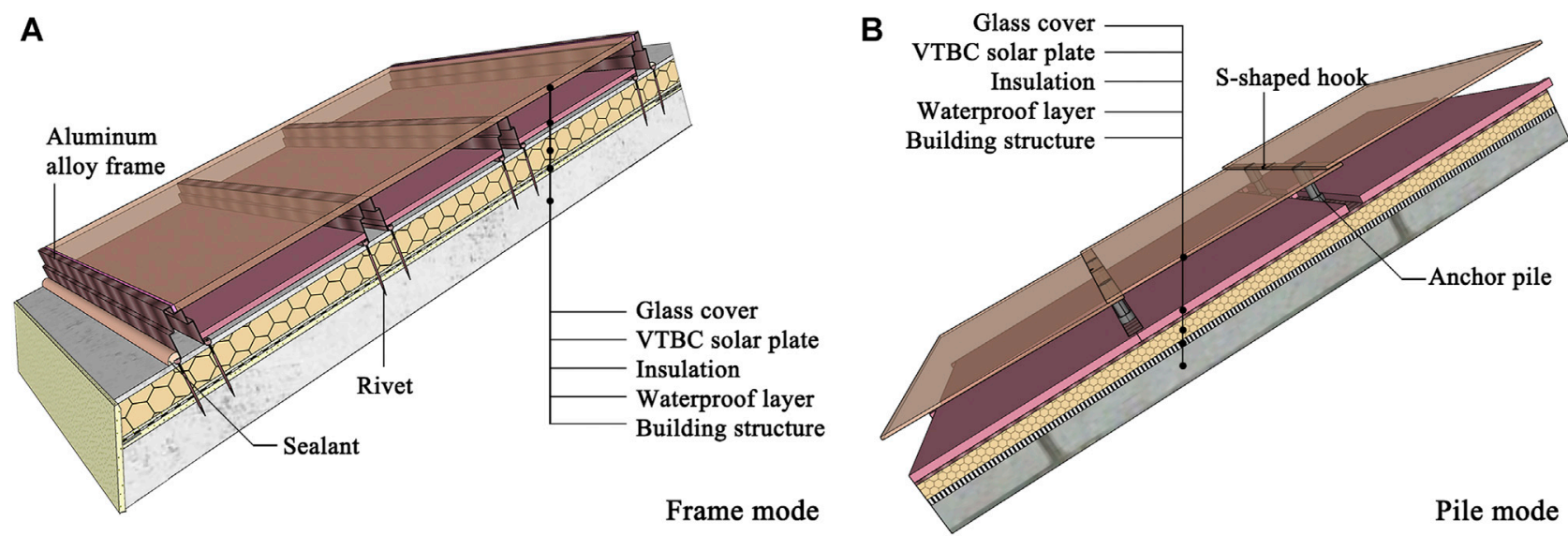

FIGURE 1 | Structural forms of the ceramic absorber integration pattern.

layer at the back. The tested efficiency of this collector is approximately 69\% (Fabrizio, 2012).

\section{PV/T Collectors}

In addition to the above solar thermal collectors, $\mathrm{PV} / \mathrm{T}$ collectors have good potential for solar greenhouses (Jouhara et al., 2016; Gorjian et al., 2021). Hybrid PV/T systems are combination of solar-thermal devices and solar-electric devices (Arefin, 2019). In these systems, the working medium [air (Tiwari and Tiwari, 2017) or liquid (Kirchner and Giovannetti, 2018)] extracts the excess generated heat from PV modules and improves the overall electric efficiency. Then, the extracted heat is used in low-to medium-temperature applications (Al-Waeli et al., 2017; Gorjian et al., 2020b). Researchers have performed numerical simulations and experimental testing regarding $\mathrm{PV} / \mathrm{T}$ greenhouses (Vadiee and Yaghoubi, 2016; Singh et al., 2018). An experiment showed that under $1095 \mathrm{~W} / \mathrm{m}^{2}$ radiation the instantaneous efficiency of a $\mathrm{PV} / \mathrm{T}$ greenhouse system is $32.2 \%$ ( Wu et al., 2019).

\section{INSTALLATION LOCATIONS OF SOLAR COLLECTORS IN GREENHOUSE PROJECTS}

For solar collectors, four installation locations are normally used in greenhouse projects. First, solar collectors mounted on the south roof have better efficiency (Nayak and Tiwari, 2008). However, in this mode, the devices severely shade sunlight, which may lead to a reduction in agricultural production. To solve this problem, semitransparent $\mathrm{PV} / \mathrm{T}$ collectors installed underneath greenhouse roofs can act as opaque envelopes (Zhi et al., 2018). Second, collectors installed on the north roof, or sometimes a small flat roof on the top, have a less negative influence on crops (Cossu et al., 2010; Yano et al., 2010). However, the system thermal performance is restricted because of poor orientation and relatively insufficient collector area.
Third, placing collectors away from the greenhouse is a feasible way to capture sunlight for both solar devices and vegetables. However, compared with crop planting, such an installation may require larger land (Fabrizio, 2012). Solar collectors of the aforementioned three integration types are placed outside the greenhouses. The heat collected by the collectors must be transported into the greenhouse before heating the indoor air or soil, which may lead to thermal loss and material waste.

Collectors installed on the south surface of the backwall may solve the problems listed above. Moreover, this mode not only shares the transparent cover of the greenhouse with solar collectors but also elevates the thermal performance of the backwall. Therefore, in greenhouses with a solid backwall, such as quadrant-shaped (Wang et al., 2014) and chapelshaped greenhouses (ELkhadraoui et al., 2015), solar collectors or absorbers can be installed on the inner surface of the wall.

\section{HEAT RELEASE IN ACTIVE SOLAR GREENHOUSES}

Heat release systems in active solar greenhouses mainly include basal heating, backwall heating, and air heating systems.

\section{Basal Heating System}

Basal heat distribution systems are usually hot water radiated along pipes (horizontal or vertical) throughout the greenhouse floor (Ghani et al., 2019). Heating systems placed under crops avoid the temperature stratification and Sun shading that occurs in a greenhouse and provide a moderate temperature (approximately $40^{\circ} \mathrm{C}$ ). In the case of bottom heating, heat is transferred directly to the crop soil, and the root temperature should not exceed $25^{\circ} \mathrm{C}$ to avoid the risk of damaging the plant rhizosphere. However, these temperature ranges impose a heat output limitation on the radiant system, which cannot exceed 50-60 W/m² (ASHRAE, 2007). 


\section{Backwall Heating System}

Backwall heating systems are usually associated with solar absorbers mounted on the backwall of the greenhouse ( $\mathrm{Lu}$ et al., 2017; Esmaeli and Roshandel, 2020). These systems have two operation modes: "absorber radiation mode" (collecting loop only) and "absorber + basal radiation mode" (collection and heating loops).

The authors conducted a greenhouse project with a dual-mode heating system in the Tacheng Basin, China. In the absorber radiation mode, the floor heating loop is closed. The absorbers collect solar heat, convey most of the heat into the water tank, and release the remaining heat into the greenhouse by absorber radiation. The heat collected from the Sun circulates between the absorbers and the tank beneath the backwall to indirectly increase the indoor air temperature. In the floor radiation mode, both the collecting loop and heating loop are manipulated to heat the water in the tank and the soil in the greenhouse. The solar energy collected by the absorbers heats not only the indoor air but also the soil matrix through floor coils. This mode is controlled by both schedule and temperature. Via experimental testing, it was found that the system efficiency of the floor radiation mode is better than that of the absorber radiation mode.

\section{Air Heating System}

Air heating is another kind of heating system in active greenhouses. The air may flow over, under, or on both sides of an absorber. A flat-panel solar air collection system for greenhouse solar heating using phase change materials (PCMs) can be operated in both the single-pass mode and the chargingdischarging mode (Benli and Durmuş, 2009). For the single-pass mode, air is drawn from the back end of the first collector through the back end of the second collector. For the charging-discharging mode, during the charging process, hot air from the air collectors circulates through the heat exchanger, and the heat is stored in the PCM. During the discharging process, the latent heat is released and the PCM solidifies.

\section{HEAT STORAGE IN SOLAR GREENHOUSES}

Solar thermal energy can be stored as sensible heat, latent heat, reaction heat, or a combination of the three (Gençer and Agrawal, 2018). Most agricultural applications are short-term (daily) storage (Zhou et al., 2017) that can handle only a small portion of the heat load and may not be sufficient during continuous overcast or rainy days. In contrast, long-term (seasonal) storage, which uses excess heat collected in summer to compensate for the heating shortages in winter, is an attractive option (Zhang et al., 2015).

\section{Short-Term Heat Storage}

In short-term heat storage systems, water, backwalls, and PCMs are used as storage media.

The most commonly used short-term heat storage medium is water. Researchers have developed a tank temperature model that predicts the water temperatures within the tank with an average accuracy of $0.4^{\circ} \mathrm{C}$ (Lu et al., 2017). Moreover, a general correlation between the water volume $(V)$ and solar greenhouse area $(A)$ was $V=0.036 A+1.603\left(R^{2}=0.7661\right)$ (Sethi and Sharma, 2008). In addition to water storage tanks, plastic bags or ground pipes filled with water can be placed in solar greenhouses along the paths between crop lines, or water barrels along the backwalls. These simple devices can be used both as heat storage media and as solar collectors (Sethi and Sharma, 2007).

Backwalls also have the potential to store solar thermal energy. Researchers have developed passive backwalls with locally available inexpensive materials such as rammed-earth, gravel, aerocrete bricks, concrete hollow blocks, and hollow expandable polystyrene blocks in China (Zhang et al., 2020).

PCMs are generally only used as short-term storage media (Amirahmad et al., 2021) due to the lack of long-term stability (Zhou et al., 2012). PCMs are classified into organic, inorganic and eutectic types (Akeiber et al., 2016). Among these types, in organic ones are most applied in building constructions (Milián et al., 2017). PCMs typically convert the solid-liquid stage between 15 and $45^{\circ} \mathrm{C}$ and are suited for indirect gain systems in the range of $20-40^{\circ} \mathrm{C}$ (Rempel and Rempel, 2013). PCMs store 5-14 times more heat per unit volume than conventional storage materials and last longer (Ziapour and Hashtroudi, 2017). In terms of building application, PCMs are primarily used in thin components, such as PCM-impregnated gypsum boards, because a large heat capacity is available at a thickness of less than $2.5 \mathrm{~cm}$ (Kuznik et al., 2011). In addition, PCMs can be used as an alternative to low-volume water encapsulated in internal storage tanks, backwalls, thin tubes or pouches (Pasupathy et al., 2008). The heat absorption and transfer mode of thin PCM walls is suited for solar greenhouses that need stable heating at night (Rempel and Rempel, 2013).

\section{Long-Term Heat Storage}

Long-term or seasonal energy storage is an effective solution to overcome the natural imbalance between supply and demand periods (Wang et al., 2017). This subsection mainly summarizes the following three long-term heat storage systems: the ground source heat pump (GSHP) system, the rock-bed heat storage system, and the soil heat storage system.

First, most seasonal heat storage systems use heat pump systems as their heating sources. Research has proved that the GSHP systems used in solar greenhouses have advantages over conventional systems (Noorollahi et al., 2016). However, the relatively high cost of GSHP systems, especially heat pumps, has prevented the system from being widely used in agricultural production, especially in developing countries. Although improved systems such as PV/GSHP and PCM/GSHP have been invented (Anifantis et al., 2017) to make GSHP environmentally friendly and energy efficient, their initial costs are even higher.

Second, to address the energy imbalance and high cost, some scientists filled two excavated canals in the greenhouse with rocks to increase its heat storage (Jain, 2005). The results showed that the nighttime indoor air temperature in the rock-bed greenhouse increased by approximately $10^{\circ} \mathrm{C}$ compared with the reference greenhouse (Kürklü et al., 2003). The data collected indicate that the most commonly used rock-bed material is gravel with 
diameters of $20-100 \mathrm{~mm}$. The empirical relationship between the total heat capacity of the rocks used $\left(C_{\mathrm{r}}\right)$ and the solar greenhouse area $(A)$ is $C_{\mathrm{r}}=46.375 A+14,483\left(R^{2}=0.8731\right)$ (Sethi and Sharma, 2008).

Third, in recent years, soil borehole heat storage technology has been introduced into greenhouse heating (Xu et al., 2014). Unlike traditional underground heating systems, the system does not require a heat pump. Therefore, the cost is greatly reduced. The experimental results showed that the system energy loss and the soil heat loss accounted for 48.0 and $7.3 \%$ of the total energy collected by the solar collectors, respectively. Soil heat loss is not cross-seasonal storage loss, but summer loss. The underground soil temperature remained high for longer. Therefore, the seasonal heat energy storage system was feasible (Zhang et al., 2015).

\section{DISCUSSION}

This paper reviews the energy performance of some recent solar thermal technologies that have helped reduce the fossil energy demand for greenhouse microclimatic control to enable intensive crop production. First, solar collector materials include metal, glass, ceramic, and plastic. Among these collectors, ceramic-based collectors have the lowest investment cost and the longest service life, while glass-based collectors usually have the highest efficiency. In greenhouses with a solid backwall, solar collectors are installed on the inner surface of the north wall to ensure the best efficiency. Second, heat release systems in active solar greenhouses mainly include basal heating, backwall heating, and air heating systems. A combination system may be adopted according to the plant requirements. Third, most agricultural

\section{REFERENCES}

Akeiber, H., Nejat, P., Majid, M. Z. A., Wahid, M. A., Jomehzadeh, F., Zeynali Famileh, I., et al. (2016). A Review on Phase Change Material (PCM) for Sustainable Passive Cooling in Building Envelopes. Renew. Sustain. Energ. Rev. 60, 1470-1497. doi:10.1016/j.rser.2016.03.036

Akram, N., Montazer, E., Kazi, S. N., Soudagar, M. E. M., Ahmed, W., Zubir, M. N. M., et al. (2021). Experimental Investigations of the Performance of a Flat-Plate Solar Collector Using Carbon and Metal Oxides Based Nanofluids. Energy 227, 120452. doi:10.1016/j.energy.2021.120452

Al-Waeli, A. H. A., Sopian, K., Kazem, H. A., and Chaichan, M. T. (2017). Photovoltaic/Thermal (PV/T) Systems: Status and Future Prospects. Renew. Sustain. Energ. Rev. 77, 109-130. doi:10.1016/j.rser.2017.03.126

Amirahmad, A., Maglad, A. M., Mustafa, J., and Cheraghian, G. (2021). Loading PCM into Buildings Envelope to Decrease Heat Gain-Performing Transient Thermal Analysis on Nanofluid Filled Solar System. Front. Energ. Res. 9, 1-10. doi:10.3389/fenrg.2021.727011

Anifantis, A. S., Colantoni, A., and Pascuzzi, S. (2017). Thermal Energy Assessment of a Small Scale Photovoltaic, Hydrogen and Geothermal Stand-Alone System for Greenhouse Heating. Renew. Energ. 103, 115-127. doi:10.1016/j.renene.2016.11.031

Arefin, M. A. (2019). Analysis of an Integrated Photovoltaic thermal System by Top Surface Natural Circulation of Water. Front. Energ. Res. 7. doi:10.3389/ fenrg.2019.00097

ASHRAE (2007). Environmental Control for Animals and Plants. USA: ASHRAE Applications Handbook. Available at: https://www.docin.com/p-1565512894. html. applications are short-term storage, while long-term storage is an attractive option.

Future studies on active solar greenhouses may focus on the aspects of microclimate prediction, long-term heat storage, and system optimization: 1) the microclimate prediction at unsampled points within greenhouses according to theoretical models, including not only air and soil temperatures but also humidity, ventilation, irradiation, $\mathrm{CO}_{2}$ concentration, and lightning; 2) the model of latent heat storage efficiency for greenhouse heating, especially that of the borehole thermal energy storage, aquifer thermal energy storage and new PCMs; and 3) the cost-benefit analytical tool to determine the optimal configuration of a heat storage-release system, such as weighing additional devices cost versus yield increase at higher indoor temperatures.

\section{AUTHOR CONTRIBUTIONS}

The author confirms being the sole contributor of this work and has approved it for publication.

\section{FUNDING}

This work was funded by the Chengdu Key Research Base of Philosophy and Social Science (No. CCRC 2020-4), the Sichuan Province Science and Technology Support Program (No. 2020YFS0309), and the National Natural Science Foundation of China (No. 51778350). Open access punlication fees will be paid by these research programs and School of Architecture and Civil Engineering, Xihua University.

Attar, I., Naili, N., Khalifa, N., Hazami, M., and Farhat, A. (2013). Parametric and Numerical Study of a Solar System for Heating a Greenhouse Equipped with a Buried Exchanger. Energ. Convers. Manage. 70, 163-173. doi:10.1016/ j.enconman.2013.02.017

Benli, H., and Durmuş, A. (2009). Performance Analysis of a Latent Heat Storage System with Phase Change Material for New Designed Solar Collectors in Greenhouse Heating. Solar Energy 83, 2109-2119. doi:10.1016/ j.solener.2009.07.005

Brötje, S., Kirchner, M., and Giovannetti, F. (2018). Performance and Heat Transfer Analysis of Uncovered Photovoltaic-thermal Collectors with Detachable Compound. Solar Energy 170, 406-418. doi:10.1016/ j.solener.2018.05.030

Chopra, K., Tyagi, V. V., Pandey, A. K., and Sari, A. (2018). Global Advancement on Experimental and thermal Analysis of Evacuated Tube Collector with and without Heat Pipe Systems and Possible Applications. Appl. Energ. 228, 351-389. doi:10.1016/j.apenergy.2018.06.067

Chopra, K., Tyagi, V. V., Pandey, A. K., Sharma, R. K., and Sari, A. (2020). PCM Integrated Glass in Glass Tube Solar Collector for Low and Medium Temperature Applications: Thermodynamic \& Techno-Economic Approach. Energy 198, 117238. doi:10.1016/j.energy.2020.117238

Cossu, M., Murgia, L., Caria, M., and Pazzona, A. (2010). Economic Feasibility Study of Semitransparent Photovoltaic Technology Integrated on Greenhouse Covering Structures. Int. Conf. Ragusa SHWA 2010, 648-655. doi:10.13140/ 2.1.1564.9921

Ding, D., He, W., and Liu, C. (2021). Mathematical Modeling and Optimization of Vanadium-Titanium Black Ceramic Solar Collectors. Energies 14, 1-20. doi:10.3390/en14030618 
Ding, D. (2018). Mechanism and Optimization Design of Vi-Ti Black Ceramic Solar Collecting Technologies Utilized in Rural Residence (In Chinese). $\mathrm{PhD}$ thesis. Jinan: Shandong Jianzhu University.

ELkhadraoui, A., Kooli, S., Hamdi, I., and Farhat, A. (2015). Experimental Investigation and Economic Evaluation of a New Mixed-Mode Solar Greenhouse Dryer for Drying of Red Pepper and Grape. Renew. Energ. 77, 1-8. doi:10.1016/j.renene.2014.11.090

Esmaeli, H., and Roshandel, R. (2020). Optimal Design for Solar Greenhouses Based on Climate Conditions. Renew. Energ. 145, 1255-1265. doi:10.1016/ j.renene.2019.06.090

Fabrizio, E. (2012). Energy Reduction Measures in Agricultural Greenhouses Heating: Envelope, Systems and Solar Energy Collection. Energy and Buildings 53, 57-63. doi:10.1016/j.enbuild.2012.07.003

Gençer, E., and Agrawal, R. (2018). Toward Supplying Food, Energy, and Water Demand: Integrated Solar Desalination Process Synthesis with Power and Hydrogen Coproduction. Resour. Conservation Recycling 133, 331-342. doi:10.1016/j.resconrec.2018.01.030

Ghani, S., Bakochristou, F., ElBialy, E. M. A. A., Gamaledin, S. M. A., Rashwan, M. M., Abdelhalim, A. M., et al. (2019). Design Challenges of Agricultural Greenhouses in Hot and Arid Environments - A Review. Eng. Agric. Environ. Food 12, 48-70. doi:10.1016/j.eaef.2018.09.004

Gorjian, S., Calise, F., Kant, K., Ahamed, M. S., Copertaro, B., Najafi, G., et al. (2021). A Review on Opportunities for Implementation of Solar Energy Technologies in Agricultural Greenhouses. J. Clean. Prod. 285, 124807. doi:10.1016/j.jclepro.2020.124807

Gorjian, S., Ebadi, H., Calise, F., Shukla, A., and Ingrao, C. (2020a). A Review on Recent Advancements in Performance Enhancement Techniques for LowTemperature Solar Collectors. Energ. Convers. Manage. 222, 113246. doi:10.1016/j.enconman.2020.113246

Gorjian, S., Ghobadian, B., Ebadi, H., Ketabchi, F., and Khanmohammadi, S. (2020b). Applications of Solar PV Systems in Desalination Technologies. Photovoltaic Solar Energ. Convers. 2020, 237-274. doi:10.1016/B978-0-12819610-6.00008-9

Hassanien, R. H. E., Li, M., and Dong Lin, W. (2016). Advanced Applications of Solar Energy in Agricultural Greenhouses. Renew. Sustain. Energ. Rev. 54, 989-1001. doi:10.1016/j.rser.2015.10.095

Jain, D. (2005). Modeling the Performance of Greenhouse with Packed Bed thermal Storage on Crop Drying Application. J. Food Eng. 71, 170-178. doi:10.1016/j.jfoodeng.2004.10.031

Jeon, J., Park, S., and Lee, B. J. (2016). Analysis on the Performance of a Flat-Plate Volumetric Solar Collector Using Blended Plasmonic Nanofluid. Solar Energy 132, 247-256. doi:10.1016/j.solener.2016.03.022

Jona, R., and Rosso, L. (2008). Composite Translucent thermal Solar Collector. United States Patent Application Publication, US 2008/047547 A1.

Jouhara, H., Milko, J., Danielewicz, J., Sayegh, M. A., Szulgowska-Zgrzywa, M., Ramos, J. B., et al. (2016). The Performance of a Novel Flat Heat Pipe Based thermal and PV/T (Photovoltaic and thermal Systems) Solar Collector that Can Be Used as an Energy-Active Building Envelope Material. Energy 108, 148-154. doi:10.1016/j.energy.2015.07.063

Kasaeian, A., Daneshazarian, R., Rezaei, R., Pourfayaz, F., and Kasaeian, G. (2017). Experimental Investigation on the thermal Behavior of Nanofluid Direct Absorption in a Trough Collector. J. Clean. Prod. 158, 276-284. doi:10.1016/j.jclepro.2017.04.131

Kelly, C., Sen, B., and Tatari, O. (2020). A System Dynamics Analysis of the Alternative Roofing Market and its Potential Impacts on Urban Environmental Problems: A Case Study in Orlando, Florida. Resour. Conservation Recycling 153, 104556. doi:10.1016/j.resconrec.2019.104556

Kim, Y. S., Balkoski, K., Jiang, L., and Winston, R. (2013). Efficient Stationary Solar thermal Collector Systems Operating at a Medium-Temperature Range. Appl. Energ. 111, 1071-1079. doi:10.1016/j.apenergy.2013.06.051

Kürklü, A., Bilgin, S., and Özkan, B. (2003). A Study on the Solar Energy Storing Rock-Bed to Heat a Polyethylene Tunnel Type Greenhouse. Renew. Energ. 28, 683-697. doi:10.1016/S0960-1481(02)00109-X

Kuznik, F., David, D., Johannes, K., and Roux, J.-J. (2011). A Review on Phase Change Materials Integrated in Building walls. Renew. Sustain. Energ. Rev. 15, 379-391. doi:10.1016/j.rser.2010.08.019

Liang, H., Wang, F., Yang, L., Cheng, Z., Shuai, Y., and Tan, H. (2021). Progress in Full Spectrum Solar Energy Utilization by Spectral Beam Splitting Hybrid PV/T
System. Renew. Sustain. Energ. Rev. 141, 110785. doi:10.1016/ j.rser.2021.110785

Lu, W., Zhang, Y., Fang, H., Ke, X., and Yang, Q. (2017). Modelling and Experimental Verification of the thermal Performance of an Active Solar Heat Storage-Release System in a Chinese Solar Greenhouse. Biosyst. Eng. 160, 12-24. doi:10.1016/j.biosystemseng.2017.05.006

Milián, Y. E., Gutiérrez, A., Grágeda, M., and Ushak, S. (2017). A Review on Encapsulation Techniques for Inorganic Phase Change Materials and the Influence on Their Thermophysical Properties. Renew. Sustain. Energ. Rev. 73, 983-999. doi:10.1016/j.rser.2017.01.159

Nayak, S., and Tiwari, G. N. (2008). Energy and Exergy Analysis of Photovoltaic/ thermal Integrated with a Solar Greenhouse. Energy and Buildings 40, 2015-2021. doi:10.1016/j.enbuild.2008.05.007

Noorollahi, Y., Bigdelou, P., Pourfayaz, F., and Yousefi, H. (2016). Numerical Modeling and Economic Analysis of a Ground Source Heat Pump for Supplying Energy for a Greenhouse in Alborz Province, Iran. J. Clean. Prod. 131, 145-154. doi:10.1016/j.jclepro.2016.05.059

Ozgener, O., and Hepbasli, A. (2005). Experimental Performance Analysis of a Solar Assisted Ground-Source Heat Pump Greenhouse Heating System. Energy and Buildings 37, 101-110. doi:10.1016/j.enbuild.2004.06.003

Papadimitratos, A., Sobhansarbandi, S., Pozdin, V., Zakhidov, A., and Hassanipour, F. (2016). Evacuated Tube Solar Collectors Integrated with Phase Change Materials. Solar Energy 129, 10-19. doi:10.1016/ j.solener.2015.12.040

Pasupathy, A., Velraj, R., and Seeniraj, R. V. (2008). Phase Change Material-Based Building Architecture for thermal Management in Residential and Commercial Establishments. Renew. Sustain. Energ. Rev. 12, 39-64. doi:10.1016/ j.rser.2006.05.010

Ramírez-Minguela, J. J., Alfaro-Ayala, J. A., Rangel-Hernández, V. H., UribeRamírez, A. R., Mendoza-Miranda, J. M., Pérez-García, V., et al. (2018). Comparison of the Thermo-Hydraulic Performance and the Entropy Generation Rate for Two Types of Low Temperature Solar Collectors Using CFD. Solar Energy 166, 123-137. doi:10.1016/j.solener.2018.03.050

Rempel, A., and Rempel, A. (2013). Rocks, Clays, Water, and Salts: Highly Durable, Infinitely Rechargeable, Eminently Controllable thermal Batteries for Buildings. Geosciences 3, 63-101. doi:10.3390/geosciences3010063

Said, Z., Saidur, R., Sabiha, M. A., Hepbasli, A., and Rahim, N. A. (2016). Energy and Exergy Efficiency of a Flat Plate Solar Collector Using pH Treated $\mathrm{Al}_{2} \mathrm{O}_{3}$ Nanofluid. J. Clean. Prod. 112, 3915-3926. doi:10.1016/ j.jclepro.2015.07.115

Sethi, V. P., and Sharma, S. K. (2007). Experimental and Economic Study of a Greenhouse thermal Control System Using Aquifer Water. Energ. Convers. Manage. 48, 306-319. doi:10.1016/j.enconman.2006.04.003

Sethi, V. P., and Sharma, S. K. (2008). Survey and Evaluation of Heating Technologies for Worldwide Agricultural Greenhouse Applications. Solar Energy 82, 832-859. doi:10.1016/j.solener.2008.02.010

Singh, G., Jain, V., and Singh, A. (2018). Adaptive Network Architecture and Firefly Algorithm for Biogas Heating Model Aided by Photovoltaic thermal Greenhouse System. Energ. Environ. 29, 1073-1097. doi:10.1177/ $0958305 \times 18768819$

Sohani, A., Shahverdian, M. H., Sayyaadi, H., Samiezadeh, S., Doranehgard, M. H., Nizetic, S., et al. (2021). Selecting the Best Nanofluid Type for A Photovoltaic thermal (PV/T) System Based on Reliability, Efficiency, Energy, Economic, and Environmental Criteria. J. Taiwan Inst. Chem. Eng. 124, 351-358. doi:10.1016/ j.jtice.2021.02.027

Teles, M. D. P. R., Ismail, K. A. R., and Arabkoohsar, A. (2019). A New Version of a Low Concentration Evacuated Tube Solar Collector: Optical and thermal Investigation. Solar Energy 180, 324-339. doi:10.1016/ j.solener.2019.01.039

Tiwari, S., and Tiwari, G. N. (2017). Energy and Exergy Analysis of a Mixed-Mode Greenhouse-type Solar Dryer, Integrated with Partially Covered N-PVT Air Collector. Energy 128, 183-195. doi:10.1016/j.energy.2017.04.022

Tong, X., Sun, Z., Sigrimis, N., and Li, T. (2018). Energy Sustainability Performance of a Sliding Cover Solar Greenhouse: Solar Energy Capture Aspects. Biosyst. Eng. 176, 88-102. doi:10.1016/j.biosystemseng.2018.10.008

Vadiee, A., and Yaghoubi, M. (2016). Exergy Analysis of the Solar Blind System Integrated with a Commercial Solar Greenhouse. Int. J. Renew. Energ. Res. 6, 1189-1199. 
Wang, J., Li, S., Guo, S., Ma, C., Wang, J., and Jin, S. (2014). Simulation and Optimization of Solar Greenhouses in Northern Jiangsu Province of China. Energy and Buildings 78, 143-152. doi:10.1016/j.enbuild.2014.04.006

Wang, T., Wu, G., Chen, J., Cui, P., Chen, Z., Yan, Y., et al. (2017). Integration of Solar Technology to Modern Greenhouse in China: Current Status, Challenges and prospect. Renew. Sustain. Energ. Rev. 70, 1178-1188. doi:10.1016/j.rser.2016.12.020

Wu, G., Yang, Q., Fang, H., Zhang, Y., Zheng, H., Zhu, Z., et al. (2019). Photothermal/day Lighting Performance Analysis of a Multifunctional Solid Compound Parabolic Concentrator for an Active Solar Greenhouse Roof. Solar Energy 180, 92-103. doi:10.1016/j.solener.2019.01.007

Wu, H., MacDonald, G. K., Galloway, J. N., Zhang, L., Gao, L., Yang, L., et al. (2021). The Influence of Crop and Chemical Fertilizer Combinations on Greenhouse Gas Emissions: A Partial Life-Cycle Assessment of Fertilizer Production and Use in China. Resour. Conservation Recycling 168, 105303. doi:10.1016/j.resconrec.2020.105303

Xu, J., Li, Y., Wang, R. Z., and Liu, W. (2014). Performance Investigation of a Solar Heating System with Underground Seasonal Energy Storage for Greenhouse Application. Energy 67, 63-73. doi:10.1016/j.energy.2014.01.049

Yang, Y., Wang, Q., Xiu, D., Zhao, Z., and Sun, Q. (2013). A Building Integrated Solar Collector: All-Ceramic Solar Collector. Energy and Buildings 62, 15-17. doi:10.1016/j.enbuild.2013.03.002

Yano, A., Kadowaki, M., Furue, A., Tamaki, N., Tanaka, T., Hiraki, E., et al. (2010). Shading and Electrical Features of a Photovoltaic Array Mounted inside the Roof of an East-West Oriented Greenhouse. Biosyst. Eng. 106, 367-377. doi:10.1016/j.biosystemseng.2010.04.007

Zhang, L., Xu, P., Mao, J., Tang, X., Li, Z., and Shi, J. (2015). A Low Cost Seasonal Solar Soil Heat Storage System for Greenhouse Heating: Design and Pilot Study. Appl. Energ. 156, 213-222. doi:10.1016/j.apenergy.2015.07.036

Zhang, X., Lv, J., Dawuda, M. M., Xie, J., Yu, J., Gan, Y., et al. (2019). Innovative Passive Heat-Storage walls Improve thermal Performance and Energy Efficiency in Chinese Solar Greenhouses for Non-arable Lands. Solar Energy 190, 561-575. doi:10.1016/j.solener.2019.08.056

Zheng, W., Zhang, H., You, S., Fu, Y., and Zheng, X. (2017). Thermal Performance Analysis of a Metal Corrugated Packing Solar Air Collector in Cold Regions. Appl. Energ. 203, 938-947. doi:10.1016/j.apenergy.2017.06.016
Zhi Li, L. I., Yano, A., Marco Cossu, M., Yoshioka, H., Kita, I., and Ibaraki, Y. (2018). Shading and Electric Performance of a Prototype Greenhouse Blind System Based on Semi-transparent Photovoltaic Technology. J. Agric. Meteorol. 74, 114-122. doi:10.2480/agrmet.d-17-00047

Zhou, D., Zhao, C. Y., and Tian, Y. (2012). Review on thermal Energy Storage with Phase Change Materials (PCMs) in Building Applications. Appl. Energ. 92, 593-605. doi:10.1016/j.apenergy.2011.08.025

Zhou, N., Yu, Y., Yi, J., and Liu, R. (2017). A Study on thermal Calculation Method for a Plastic Greenhouse with Solar Energy Storage and Heating. Solar Energy 142, 39-48. doi:10.1016/j.solener.2016.12.016

Ziapour, B. M., and Hashtroudi, A. (2017). Performance Study of an Enhanced Solar Greenhouse Combined with the Phase Change Material Using Genetic Algorithm Optimization Method. Appl. Therm. Eng. 110, 253-264. doi:10.1016/ j.applthermaleng.2016.08.153

Zukowski, M., and Woroniak, G. (2017). Experimental Testing of Ceramic Solar Collectors. Solar Energy 146, 532-542. doi:10.1016/j.solener.2017.03.022

Żukowski, M., Woroniak, G., and Piotrowska-Woroniak, J. (2019). Experimental Research and Numerical Simulations of a Ceramic Panel Used for Solar Energy Conversion. Solar Energy 194, 27-36. doi:10.1016/j.solener.2019.10.028

Conflict of Interest: The author declares that the research was conducted in the absence of any commercial or financial relationships that could be construed as a potential conflict of interest.

Publisher's Note: All claims expressed in this article are solely those of the authors and do not necessarily represent those of their affiliated organizations, or those of the publisher, the editors and the reviewers. Any product that may be evaluated in this article, or claim that may be made by its manufacturer, is not guaranteed or endorsed by the publisher.

Copyright $\odot 2021$ Ding. This is an open-access article distributed under the terms of the Creative Commons Attribution License (CC BY). The use, distribution or reproduction in other forums is permitted, provided the original author(s) and the copyright owner(s) are credited and that the original publication in this journal is cited, in accordance with accepted academic practice. No use, distribution or reproduction is permitted which does not comply with these terms. 